\title{
Chemical and Topographic Analysis of Treated Surfaces of Five Different Commercial Dental Titanium Implants
}

\author{
Bruno Ramos Chrcanovic*, Alexsander Ribeiro Pedrosa, Maximiliano Delany Martins
}

\author{
Laboratório de Nanoscopia - LabNano, Centro de Desenvolvimento da Tecnologia Nuclear - CDTN, \\ Comissão Nacional de Energia Nuclear-CNEN, Av. Presidente Antônio Carlos, 6627, \\ Campus da UFMG, Pampulha, CEP 31270-901, Belo Horizonte, MG, Brazil
}

Received: August 22, 2011; Revised: February 7, 2012

\begin{abstract}
We present a detailed investigation of the surface characteristics of five commercial titanium implants with different surface finishing (double acid etching, anodization and incorporation of $\mathrm{Ca} / \mathrm{P}$, acid etching and deposition of $\mathrm{Ca} / \mathrm{P}$, hydroxyapatite-blasting, acid etching and $\mathrm{Ca} / \mathrm{P}-\mathrm{blasting}$ ) produced by five different manufacturers. A set of experimental techniques were employed to study the surface chemical composition and morphology: XPS, XRD, SEM, EDS, and AFM. According to the implat manufacturers, the addition of $\mathrm{Ca}$ and $\mathrm{P}$ at the implant surface is a main feature of these implants (except the double acid etched implant, which was included for comparative purpose). However, the results showed a great discrepancy on the final amount of these elements on the implant surface, which suggests a different effectiveness of the employed surface finishing methods to fix those elements on the implant surface. Our results show that only the method used by the manufacturer of hydroxyapatite-blasting surface finished implants was efficient to produce a hydroxyapatite coating. This group also showed the highest roughness parameters.
\end{abstract}

Keywords: dental implants, surface modification, chemical analysis, titanium

\section{Introduction}

Oral rehabilitation by means of endosseous dental implants is an essential issue in clinical practice. Local bone quality and systemic implications on the oral healing condition have a direct role in the success of dental implant therapy ${ }^{1}$.

Since the finding of the osseointegration concept, the characteristics of the interface between bone and implant, and possible ways to improve it, have been of particular interest in dental and orthopedic implant research. Osseointegration is defined experimentally as the close contact between bone and implant material in histological sections and, in clinical terms, as the stability and ankylosis of an implant in bone ${ }^{2}$.

Upon the placement of an implant into a surgical site, there is a cascade of molecular and cellular processes that provide for new bone growth and differentiation along the biomaterial surface ${ }^{3}$. One means to improve implant success is through methods to increase the amount of bone contact along the body of the implant. While it may seem obvious that increased surface roughness of implants leads to greater success it is not clear what aspect of "roughness" is advantageous ${ }^{4}$.

Already by the beginning of the 1980s, surface structure was identified as one of the six main factors particularly important for implant incorporation into bone ${ }^{5}$, a statement that has been confirmed in later published research. Faster and stronger bone formation may confer better stability

*e-mail: brunochrcanovic@hotmail.com during the healing process, thus allowing more rapid loading of the implant. The aim of rough surfaces is not only to increase the interlock between the implant and bone, but also to improve the bone-healing process ${ }^{4}$.

An increasing number of surface modifications are introduced and despite a majority of studies comparing 'machined' surfaces with new rough surfaces, it is not clear whether, in general, one surface modification is better than another. To further add to the confusion, not only surface topography is changed with many techniques but also surface chemistry and altered topography commonly results in a change in the chemistry and vice versa ${ }^{4}$.

The fact that the surface properties of titanium and of other biomaterials show considerable variation depending on the type of surface treatment emphasizes the necessity of surface characterization of the materials used in biological experiments. A systematic approach towards understanding the relationship between material properties and biological response is of course crucially dependent on knowledge about the surface properties of the investigated materials ${ }^{6}$.

Well-defined surface characterization provides a scientific basis for a better understanding of the effects of the implant surface on the biological response. Moreover, a more detailed study on the characterization of dental implants commercially available in Brazil is lacking. Thus, the purpose of the present study was to investigate the superficial chemical composition and surface topography of five titanium dental implants commercially available in Brazil. 


\section{Materials and Methods}

Five screw-shaped implants from different manufacturers and different surface modifications were chosen for analysis. For each type of implant two specimens were purchased in the market. The implants were all received in their original sterile packaging and only opened at the start of the investigation. They were carefully handled in order to prevent contamination during further manipulations. They were classified into five groups [model, manufacturer]: (1) double acid etching (Stylus ${ }^{\mathrm{TM}}$, SIN, São Paulo, Brazil), (2) anodization and electrochemical incorporation of $\mathrm{Ca} / \mathrm{P}$ (Vulcano Actives ${ }^{\mathrm{TM}}$, Conexão, São Paulo, Brazil), (3) acid etching and deposition of $\mathrm{Ca} / \mathrm{P}\left(\right.$ Nanotite $^{\mathrm{TM}}$, Biomet $3 \mathrm{i}$, Palm Beach Gardens, USA), (4) hydroxyapatite-blasting (HAp ceramed $^{\mathrm{TM}}$, Ceramed, Lisboa, Portugal), and (5) acid etching and $\mathrm{Ca}$ /P-blasting (Ossean ${ }^{\mathrm{TM}}$, Intra-lock, Boca Raton, USA). A detailed explanation of the surface modification methods was not available to all sample groups and was not provided by the manufacturers. From the information available, it can be said that the implants from group 3 have a dual-acid surface etching treatment followed by deposition of nanometer scale crystals of calcium phosphate (CaP). The surface treatment is by discrete crystalline deposition on the surface, not a plasma sprayed coating. The coating process for group 4 is performed by thermal spraying of hydroxyapatite (HA) on the titanium surface. The HA is heated to a molten or semi-molten state within the projection gun, and projected on a surface previously prepared. Then the material solidifies, giving rise to multiple layers that form the coating. The implants of group 5 are previously acid-etched and then blasted with particles of calcium and phosphate in clean atmosphere.

The five different titanium-treated surfaces were examined by scanning electron microscopy - SEM (JEOL, model JSM-840A, Tokyo, Japan). The SE mode with an acceleration voltage of $25 \mathrm{kV}$ was selected for SEM analysis and the vacuum pressure was maintained below $1 \times 10^{-5}$ Torr. The load current (LC) was approximately $85 \mu \mathrm{A}$. For a direct comparison of the surface morphology, the same magnification was used for all investigated implants.

In order to obtain quantitative analysis of the implant roughness, atomic force microscopy (AFM - NTegra Aura, NT-MDT, Moscow, Russia) of the implant samples was performed. AFM images were acquired in air using semicontact mode with a NSG 01 sharpened gold-coated silicon tip (nominal spring constant of $2.5-10 \mathrm{~N} / \mathrm{m}$ and nominal resonance frequency of $110-200 \mathrm{kHz}$, NT-MDT). The scanning area for the measurements was $20 \times 20 \mu \mathrm{m}^{2}$. The images obtained by AFM were characterized by $2^{\text {nd }}$ order extraction filter, using the software Image Analysis 2.1.2 (NT - MDT, Moscow, Russia). The seven surface roughness parameters calculated by the software were evaluated $\left(\mathrm{S}_{\mathrm{y}}, \mathrm{S}_{\mathrm{z}}, \mathrm{S}_{\mathrm{a}}, \mathrm{S}_{\mathrm{q}}, \mathrm{S}_{\mathrm{sk}}\right.$, and $\left.\mathrm{S}_{\mathrm{ka}}\right)$. The mean value and standard deviation of these parameters was obtained from ten satisfactory scans of each group, from random sites of the flat surface of the groove from the apex of the implants. The surface chemical composition was analyzed by energy dispersive x-ray spectroscopy - EDS (JEOL, model JXA-8900RJ, Tokyo, Japan). Two regions of the implants were evaluated: the platform, in order to analyze the type of titanium substrate (Ti/cp or Ti6Al4V), since no surface modification was present at this region, and the flat surface of the groove from the apex of the implants.

The surface chemical composition was also analyzed by X-ray photoelectron spectroscopy (XPS) using $\mathrm{Mg} \mathrm{K \alpha}$ radiation $(1253.6 \mathrm{eV})$ and a CLAM2 Electron Analyzer (VG Microtech, East Sussex, UK). XPS analysis provides more superficial information (few nanometers deep) compared to EDS, which was use to better understand the chemical profile introduced by the different modification methods. The x-ray beam was directed to middle of the threads of the implants. The base pressure was below $2.0 \times 10^{-10} \mathrm{mbar}$ during spectra data acquisition. Survey XPS data was collected from 0 to $1100 \mathrm{eV}$ of binding energy and acquired with constant pass energy of $100 \mathrm{eV}$. High resolution XPS spectra were obtained at Ti 2p, $\mathrm{O}$ 1s, C 1s, Ca 2p, P 2p, N 1s, and Si 2p, when present, with constant pass energy of $50 \mathrm{eV}$. XPS data were acquired after 30 minutes surface cleaning by $\mathrm{Ar}^{+}$sputtering. All binding energies were referenced relative to the main hydrocarbon peak (from residual hydrocarbon contamination) set at $285.0 \mathrm{eV}$. The high resolution XPS peaks were analyzed using Gaussian-Lorentzian curve fitting and Shirley peak baseline with the Xi Spectral Data Processor 32 bit version 3.0 software (XPS International, Los Altos, USA), in order to determine peak positions, areas and full-width half maximums (FWHM). The elemental surface composition was calculated by normalizing the relative spectral peak areas (A) using relative sensitivity factors $S^{7}$, as illustrated in the equation:

$$
C_{x}=\frac{A_{x}}{S_{x}} / \sum_{i} \frac{A_{i}}{S_{i}}
$$

where $\mathrm{C}_{\mathrm{x}}$ is the atomic fraction of any constituent in the sample surface.

X-ray diffraction measurements were carried out in a D/Max Ultima X-ray diffractometer (Rigaku, Tokyo, Japan), using $\mathrm{Cu}-\mathrm{K} \alpha_{1}$ radiation without any filter or monochromator, in the angle range of $10^{\circ}-90^{\circ}(2 \theta)$ with a grazing incidence of 3 degrees, so that diffraction can be made surface sensitive. The results were analyzed in Search-Match (Crystallographica, Oxford, United Kingdom) and Fullprof (CNRS, Gif sur Yvette, France) softwares. The diffraction patterns for each compound used in the comparisons were standardized by JCPDS-International Center for Diffraction Data (PCPDFWIN v.2.01, ICCD, Newton Square, USA).

The indexation of patterns of crystal structures was determined according to Cullity and Stock ${ }^{8}$. The indexing is provided by the diffraction lines with a value of $\sin ^{2} \theta$, which satisfies a certain equation for each crystal structure. For a cubic crystal, the equation:

$$
\frac{\sin ^{2} \theta}{\left(h^{2}+k^{2}+l^{2}\right)}=\frac{\lambda^{2}}{4 a^{2}}
$$

is obtained by combining the Bragg law with the plane-spacing equation for the cubic system. Patterns of hexagonal crystals can be determined by the following equation:

$$
\sin ^{2} \theta=\frac{\lambda^{2}}{4}\left[\frac{4}{3} \cdot \frac{\left(h^{2}+h k+k^{2}\right)}{a^{2}}+\frac{l^{2}}{c^{2}}\right]
$$


and the $\sin ^{2} \theta$ values in the tetragonal system must obey the relation:

$\sin ^{2} \theta=\frac{\lambda^{2}}{4 a^{2}}\left(h^{2}+k^{2}\right)+\frac{\lambda^{2}}{4 c^{2}} l^{2}$

where $h, k$ and $l$ are the Miller indices, $a$ and $c$ are the lattice parameters, $\lambda$ is the wavelength of the $X$-ray beam, and $\theta$ is the angle of diffraction in degrees.

\section{Results}

\subsection{SEM analysis}

Figures 1 a to $1 \mathrm{e}$, revealed characteristic differences at the microscopic level according to the surface modification methods used for the implant samples as measured by SEM. Group 1 implants showed surface topography subtracted by acid baths, almost like a needle-like elevation structure (Figure 1a). Pore size was 3.0-6.0 $\mu \mathrm{m}$, sometimes elongated to $10 \mu \mathrm{m}$. Group 2 implants showed a porous structure induced by breakdown phenomena during anodic oxidation like craters of volcanoes (Figure 1b). Pore size was 0.5-3.0 $\mu \mathrm{m}$. Group 3 implants also showed a needle-like elevation structure (Figure 1c), as observed in group 1, but the pore size was smaller $(0.5-2.0 \mu \mathrm{m})$. Group 4 implants showed a less homogeneous surface structure than the other groups (Figure 1d). The surface appears to be thermally melted by the spray. There was a distribution of spherical structures arranged like clusters of grapes (see detail - 10000x). Group 5 implants were mainly characterized with facets produced by blasting and fine etching pits, with some smooth areas and other very rough areas (Figure 1e).

\subsection{EDS analysis}

EDS-analysis of the surface showed titanium to be the common element in screw thread and platform in all groups, except for the screw thread region in group 4 . There was high purity of titanium in screw thread and platform in group 1, and in the platform in groups 2 and 5. Calcium, phosphor and oxygen were the additional elements found on the screw thread in group 2. Ca, $\mathrm{P}, \mathrm{O}$ and $\mathrm{C}$ were found in the screw thread of group 4; Ti was not observed. The presence of titanium, aluminum, and vanadium was observed in screw thread and platform of group 3 and in the platform of group 4. Calcium, phosphor and titanium were found in the screw thread of group 5.

\subsection{AFM analysis}

The qualitative and quantitative surface topography demonstrated different degrees of roughness. Implants of the groups 2, 3, and 5 exhibited similar roughness parameters. Groups 1 and 4 exhibited a rougher surface than the other three groups, as demonstrated by higher $\mathrm{S}_{\mathrm{y}}, \mathrm{S}_{\mathrm{z}}, \mathrm{S}_{\mathrm{q}}$, and $\mathrm{S}_{\mathrm{a}}$ parameters (Table 1).

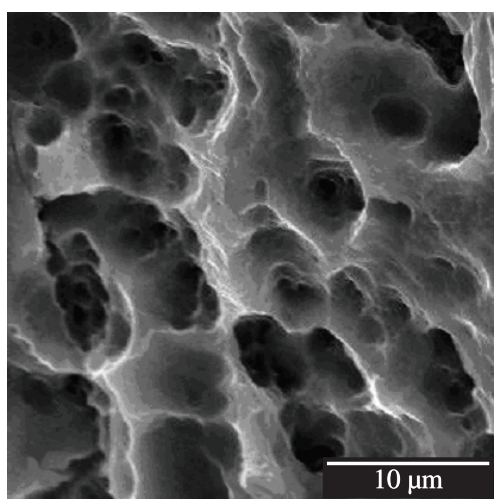

(a)

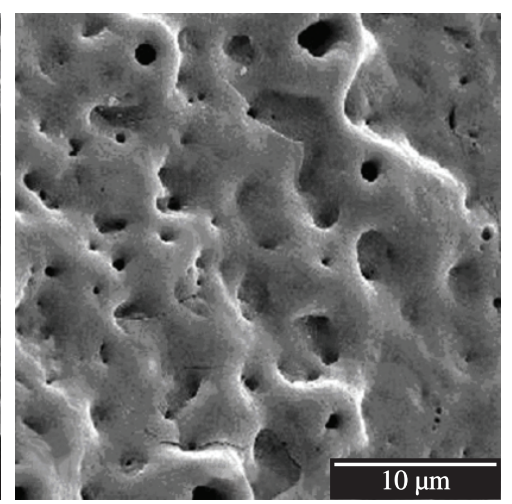

(b)

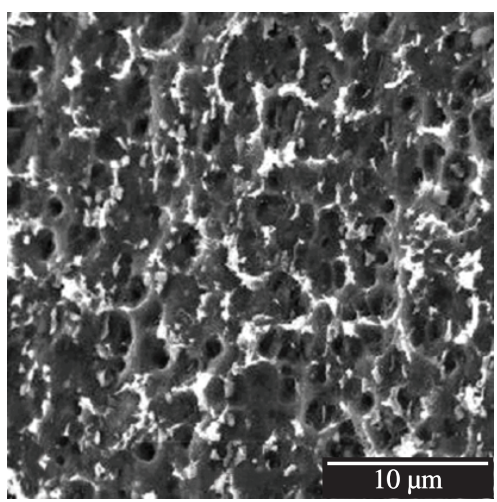

(c)

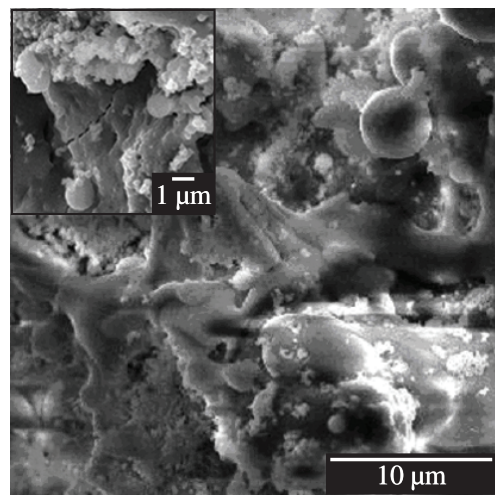

(d)

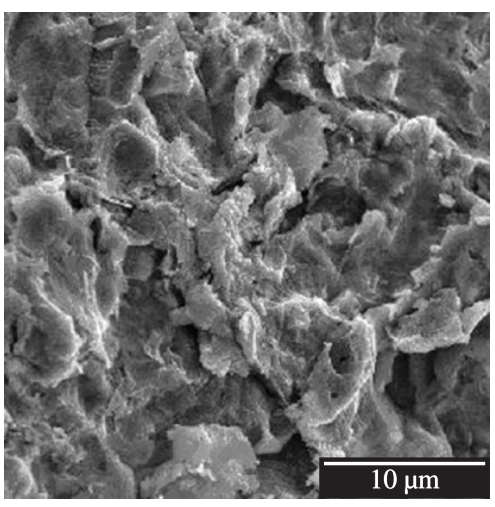

(e)

Figure 1. SEM pictures of groups 1 a); 2 b); 3 c); 4 d); and 5 e) (original magnification $3000 \times$ ). 
Table 1. Mean values $( \pm$ SD) of tridimensional roughness parameters as determined by AFM.

\begin{tabular}{cccccrrr}
\hline Group & $\begin{array}{c}\mathbf{S}_{\mathbf{y}} \\
(\mu \mathbf{m})\end{array}$ & $\begin{array}{c}\mathbf{S}_{\mathbf{z}} \\
(\mu \mathbf{m})\end{array}$ & $\begin{array}{c}\text { Average-mean } \\
\text { height }(\mu \mathbf{m})\end{array}$ & $\begin{array}{c}\mathbf{S}_{\mathbf{a}} \\
(\mu \mathbf{m})\end{array}$ & $\begin{array}{c}\mathbf{S}_{\mathbf{q}} \\
(\mu \mathbf{m})\end{array}$ & $\mathbf{S}_{\text {sk }}$ & $\mathbf{S}_{\mathbf{k u}}$ \\
\hline 1 & $3.80 \pm 1.00$ & $1.90 \pm 0.49$ & $1.88 \pm 0.69$ & $0.59 \pm 0.17$ & $0.78 \pm 0.19$ & $-0.06 \pm 0.27$ & $-0.39 \pm 0.41$ \\
2 & $2.84 \pm 0.98$ & $1.42 \pm 0.49$ & $1.45 \pm 0.60$ & $0.40 \pm 0.19$ & $0.49 \pm 0.22$ & $-0.02 \pm 0.25$ & $-0.20 \pm 0.30$ \\
3 & $2.79 \pm 0.66$ & $1.40 \pm 0.33$ & $1.33 \pm 0.39$ & $0.36 \pm 0.09$ & $0.45 \pm 0.11$ & $0.34 \pm 0.30$ & $0.26 \pm 0.79$ \\
4 & $4.33 \pm 1.01$ & $2.16 \pm 0.50$ & $2.19 \pm 0.48$ & $0.59 \pm 0.15$ & $0.74 \pm 0.18$ & $-0.12 \pm 0.13$ & $-0.16 \pm 0.30$ \\
5 & $2.96 \pm 0.34$ & $1.47 \pm 0.16$ & $1.19 \pm 0.13$ & $0.40 \pm 0.02$ & $0.49 \pm 0.03$ & $0.18 \pm 0.23$ & $-0.32 \pm 0.15$ \\
\hline
\end{tabular}

\subsection{XPS analysis}

The XPS survey spectra of as-received dental implant showed major peaks at Ti 2p, O 1s and C 1s (not presented here), except for group 4, which did not show Ti on surface. All elements except $\mathrm{Ti}$ and $\mathrm{O}$ decrease rapidly or disappear after sputtering to a depth of a few $\mathrm{nm}$, indicating that the impurities are present predominantly at the outermost surface. In all groups, the Ti peak intensities increased after sputter cleaning (except for group 4) and the carbon peaks disappeared. Surface elemental composition (\% atomic concentration), as measured by XPS analysis, and calculated by Equation 1, is presented in Table 2.

High-resolution XPS spectra of Ti $2 \mathrm{p}$ and $\mathrm{O} 1 \mathrm{~s}$ are presented in Figure 2. The O 1s spectra showed main peaks between 530.00-530.36 eV. For sputter cleaned titanium surfaces, this peak always dominates the $\mathrm{O} 1 \mathrm{~s}$ regions, as was true for all the groups but group 4. O 1s spectra were deconvoluted to $\mathrm{TiO}_{2},(\mathrm{OH})$ or $\mathrm{C}-\mathrm{O}$, and $\mathrm{Ti}-\mathrm{OH}$ or $\mathrm{C}=\mathrm{O}$. The full width at half maximum (FWHM) of O $1 \mathrm{~s}\left(\mathrm{TiO}_{2}\right)$ was smaller for group 5 implants and showed rather similar features between the other groups. The $\mathrm{O} 1 \mathrm{~s}$ spectrum of group 4 was deconvoluted to $\mathrm{O}^{2-}\left(\mathrm{PO}_{4}, \mathrm{CO}_{3}\right.$ and $\left.\mathrm{OH}\right)$, and $\mathrm{H}_{2} \mathrm{O},{ }^{9}$ with higher FWHM (Table 3 ).

The titanium spectra obtained by XPS were complex. Titanium was found to be present in the metallic state (Ti) and in the divalent $(\mathrm{TiO})$, trivalent $\left(\mathrm{TiO}_{2}\right)$ and tetravalent $\left(\mathrm{Ti}_{2} \mathrm{O}_{3}\right)$ oxide states. As already observed ${ }^{10}$, the peaks corresponding to $\mathrm{TiO}_{2}$ are by far the most prominent ones in the $\mathrm{Ti} 2 \mathrm{p}$ region.

The Ti $2 \mathrm{p}$ doublet peak, i.e., Ti 2p1/2 and Ti 2p3/2, appeared between 464.50-464.74 eV and 458.48-458.83 eV for all the implants. Ti $2 \mathrm{p} 1 / 2$ were deconvoluted to $\mathrm{TiO}_{2}$ at $464.58 \pm 0.09 \mathrm{eV}($ Mean $\pm \mathrm{SD}), \mathrm{Ti}_{2} \mathrm{O}_{3}+\mathrm{TiO}$ at $462.77 \pm 0.24 \mathrm{eV}$, and $\mathrm{Ti}$ metal at $460.89 \pm 0.68 \mathrm{eV}$ (Table 4). Ti 2p3/2 were deconvoluted to $\mathrm{TiO}_{2}$ at $458.67 \pm 0.14 \mathrm{eV}, \mathrm{Ti}_{2} \mathrm{O}_{3}+\mathrm{TiO}$ at $456.25 \pm 0.36 \mathrm{eV}$, and $\mathrm{Ti}$ metal at $453.22 \pm 1.81 \mathrm{eV}$ (Table 5). The deconvolutions were performed according to the other authors ${ }^{11}$. The FWHM was greater for group 2 implants for $\mathrm{TiO}_{2}$ peaks of Ti $2 \mathrm{p}$ and showed rather similar features between the other groups (Tables 4 and 5).

The C1s signals were curve-fitted based on three different components. The deconvolution is straightforward as well as the assignment to hydrocarbon $(285.0 \mathrm{eV}), \mathrm{C}-\mathrm{O}$ species $(\sim 286 \mathrm{eV})$ and COO species $(288-298 \mathrm{eV})^{11}$. The presence of carbon in different chemical environments is typical for titanium (and other metal) oxide surfaces. This is a consequence of the tendency of titanium surfaces to readily adsorb organic components during fabrication (e.g. lubricants) or from the ambient atmosphere during storage $\mathrm{e}^{11}$. Few additional elements were detected by XPS in very low concentrations.

\subsection{XRD analysis}

Figures $3 \mathrm{a}$ and e, show typical XRD pattern for the groups 1 to 5 , respectively. The diffraction peak positions were calculated using the Equations 2 to 4 and identified by (hkl) Miller indices. The XRD measurements identified crystal structures of Ti and titanium hydride $\left(\mathrm{TiH}_{2}\right)$ in group 1 , $\mathrm{Ti}$ and anatase $\left(\mathrm{TiO}_{2}\right)$ in group 2, Ti in group 3, Ti and HA in group 4, and $\mathrm{Ti}$ in group 5. Ti and HA have hexagonal close-packed crystal structure with lattice parameters of $\mathrm{a}=0.295 \mathrm{~nm}, \mathrm{c}=0.468 \mathrm{~nm}$, and $\mathrm{a}=0.94344 \mathrm{~nm}$, $\mathrm{c}=0.68815 \mathrm{~nm}$, respectively ${ }^{12,13}$, anatase has a tetragonal structure with lattice parameters of $\mathrm{a}=0.3785 \mathrm{~nm}$, $\mathrm{c}=0.9514 \mathrm{~nm},{ }^{14}$ and $\mathrm{TiH}_{2}$ has a face-centered cubic crystal structure with lattice parameter of $\mathrm{a}=0.4448 \mathrm{~nm}^{15}$.

\section{Discussion}

The surface elemental composition and morphology of five commercial titanium implants with different surface finishing produced by five different manufacturers have been analyzed using a complementary set of experimental techniques (SEM, EDS, AFM, XPS, and XRD). However, it is important to note that only two specimens per type of implant were investigated. With such limited sample investigation no conclusions can be drawn with regard to the degree to which these samples are typical of the manufacturer's production, neither within the particular batch nor between batches ${ }^{11}$. On the other hand, the experimental findings and the differences between the various types of surfaces turned to be characteristic for different areas of the same device as well as between the two specimens investigated per implant type ${ }^{11}$. The present results showed that surface chemistry and morphology of different commercially available clinical titanium implants differed due to surface modification techniques used during manufacturing.

\subsection{SEM analysis}

Fine differences of the pits and facets were obvious between the implants due to differences of the blasting and etching processes. Each manufacturer makes use of a specific treatment. The groups 1 and 3 showed fine structures characteristically produced by chemical etching processes. However, the two surfaces are clearly different, both as 
Table 2. Surface elemental composition (\% atomic concentration) after 30 minutes surface cleaning by $\mathrm{Ar}^{+}$sputtering, as determined by XPS (see text).

\begin{tabular}{ccrrrr}
\hline \multirow{2}{*}{ Element } & \multicolumn{5}{c}{ Implant groups } \\
\cline { 2 - 6 } & $\mathbf{1}$ & $\mathbf{2}$ & $\mathbf{3}$ & $\mathbf{4}$ & $\mathbf{5}$ \\
\hline $\mathrm{Ti}$ & 35.8 & 19.0 & 5.0 & - & 15.2 \\
$\mathrm{O}$ & 74.2 & 70.7 & 86.0 & 71.3 & 81.1 \\
$\mathrm{Ca}$ & - & 7.8 & 7.3 & 13.9 & 0.4 \\
$\mathrm{P}$ & - & 2.5 & 1.7 & 7.8 & 3.3 \\
$\mathrm{Si}$ & - & - & - & 7.0 & - \\
\hline
\end{tabular}

regards the dimensions of the surface microstructures as well as the homogeneity. In the case of the groups 4 and 5, a coarser microstructure as a consequence of a particle blasting process can be observed and a finer etch-type structure that is relatively constant in dimensions and fairly regularly distributed across the surface was superimposed on the coarser blasted structure. The electrochemical oxidation process for group 2 implants changed not only surface chemistry due to incorporation of anions from the electrolyte, but also produced a porous structure of the thick oxide layer.

\subsection{EDS analysis}

A similar pattern between the spectra of the platform in groups 3 and 4 can be observed by the EDS analysis. In these groups $\mathrm{Ti}, \mathrm{Al}$, and $\mathrm{V}$ are the substrate elements (suggesting a Ti6Al4V alloy). The group 4 showed total covering of the substrate, as none of these elements were observed in the screw thread spectrum. Ti is the substrate in groups 1,2 , and 5. Calcium was observed in groups 2, 3, 4 and 5 and $\mathrm{P}$ in groups 2, 4, and 5. The different relative intensity of calcium in these groups can be explained by the variation of surface modification techniques. The expression of $\mathrm{Ca}$ and total absence of $\mathrm{P}$ in group 3 indicates that the deposition of $\mathrm{CaP}$ compound may have been insufficient in this sample due to technical limitation.

The presence of oxygen only in groups 2 and 4 can be explained by the composition of HA and phosphates used, for its high reactivity with other elements of the environment and by the process of alkaline passivation of the surface of the implants made by these manufacturers. This element is present in all groups in the form of oxides, as showed by the XPS spectra. However, the microprobe has a relatively high profile analysis, requiring the use of more surface sensitive techniques such as XPS.

\subsection{AFM analysis}

The results of the present study demonstrate that implants from the groups 1 and 4 exhibited a rougher surface textures compared to the other groups. As the implant designs were screw-shaped the AFM scans were achieved from the flat surface of the apex of the implant, since the AFM cannot be used on implant thread. However, a flat apex area is often manufactured with another machining technique than rest of the implant (often milled instead of turned), and this will influence the final outcome. The value may therefore not be representative for rest of the implant.
It is worth noticing that a large surface roughness does not represent a problem for coated metallic implants in biomedical applications, because roughness usually ensures a better osseointegration, as compared to smoother implants ${ }^{16}$. The advantage of small increase in roughness was further demonstrated in rabbit femora and tibiae, with commercially pure titanium (cp Ti) screws attracting better bone response and greater torsional fixation when the blasting texture increased from 1.10 to $1.45 \mu \mathrm{m}$ $\left(\mathrm{S}_{\mathrm{a}} \text { parameter }\right)^{17}$. Thus, according to this previous study, an average surface roughness of about 1.0-1.4 $\mu \mathrm{m}$ seems to be most suitable for good bone-to-metal fixation, which was not observed by any of the implants studied here. The use of different roughness measurement devices, such as optical profilometer $^{18}$, confocal laser scanning profilometer ${ }^{19}$, optical laser roughness tester instrument ${ }^{20}$ or AFM in the present study may also have influenced the results. As far as the quantification of surface characterization of implants is concerned, it is at present an unresolved issue. One concerning aspect is the resolution of profilometry. The roughness of implant surfaces tends to be below the resolution of conventional mechanical techniques (the profilometric tip size, 3-5 $\mu \mathrm{m}$ ). The laser profilometer has proved to be a more suitable method to characterize the roughness of implant surfaces with a laser-focused spot of $1 \mu \mathrm{m}$ and a measuring length of some millimeters. The resolution of an AFM is even higher. The tip used in the AFM in the present study has a tip curvature radius of $10 \mathrm{~nm}$. This may also have influenced the results of roughness parameters found in this study, which were much lower than in previous studies that made measurements using a profilometer ${ }^{18-20}$. The experimental methods that uses larger scanning tips cannot resolve the finer features of the etched surfaces ${ }^{4}$, and therefore higher values of the surface roughness are expected. Moreover, higher roughness values are found for longer measured distances, in line with previous observations ${ }^{17}$. Thus, the smaller values observed in the present study may have resulted from a smaller area chosen measured by AFM for measurement $\left(20\right.$ x $20 \mu^{2}$ ) in comparison with other studies that observed higher $\mathrm{S}_{\mathrm{a}}$ but with higher measured area (typically $240 \times 245 \mu^{2}$ ), and using larger scanning tips with a profilometer ${ }^{18,19}$. This heterogeneity may have been caused by differences in measurement methods.

\subsection{XPS analysis}

It is generally accepted that the outermost atomic layer of the implant surface is a key factor in the osseointegration process. As the cell-surface interaction takes place over a few atomic distances, compositional modifications at the atomic level on the implant surface can influence the biocompatibility and the osseointegration prognosis of the implant $^{21}$. Therefore, it is very important to know accurately the surface chemical composition of titanium dental implants (as well as every other biomaterial).

Previous studies on the surface chemistry of machined, turned and blasted implants have reported $\mathrm{Ti}, \mathrm{O}$ and $\mathrm{C}$ as major elements ${ }^{10,11,22,23}$. The chemistry-modified implants have revealed the presence of $\mathrm{Ca}, \mathrm{P}, \mathrm{Mg}, \mathrm{S}, \mathrm{F}$, and $\mathrm{Na}$ in association with the used surface finishing methods ${ }^{10,22,24}$. In 
Group 1
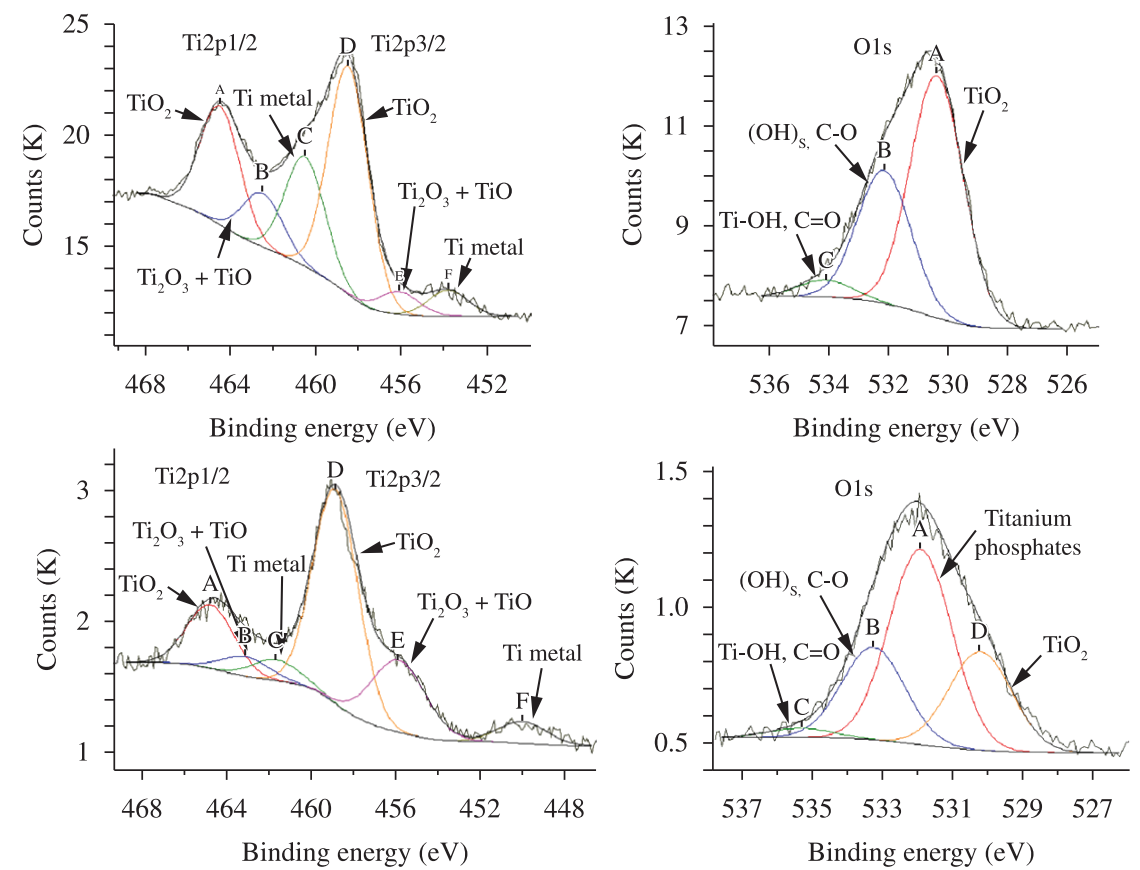

Group 2

Group 3
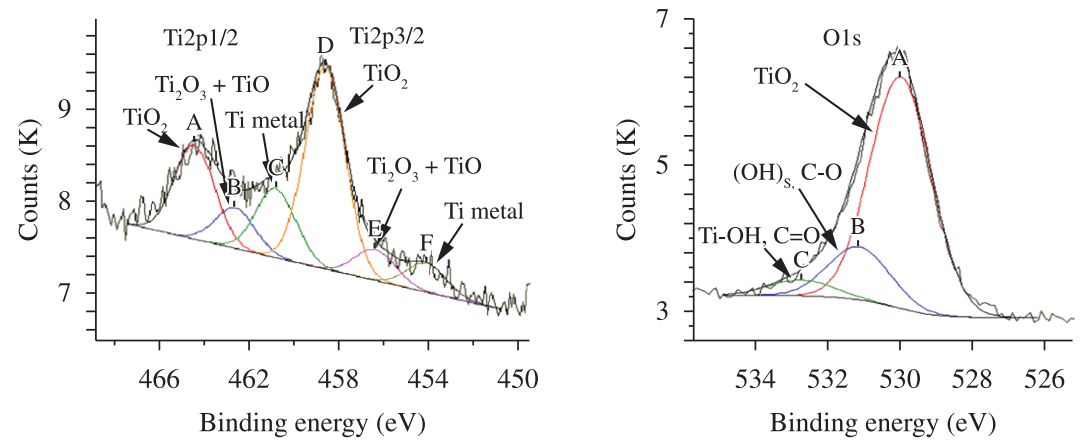

Group 4
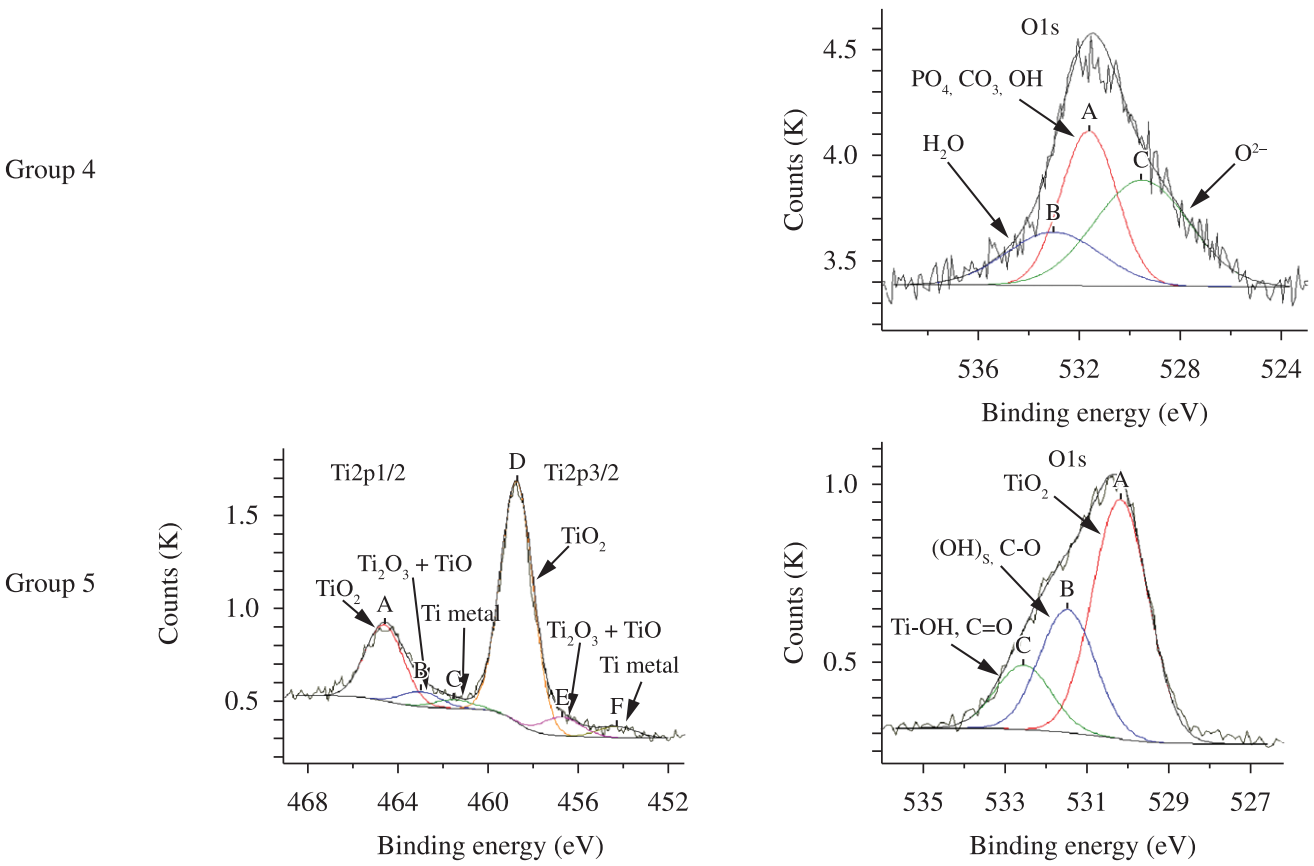

Figure 2. Ti 2p and O 1s high-resolution XPS spectra for the 5 different groups (see text for experimental details). 
Table 3. Binding energy and FWHM of O 1s components, as determined after curve fitting of the XPS high resolution spectra (see text for details).

\begin{tabular}{|c|c|c|c|c|c|c|c|}
\hline \multirow[t]{2}{*}{ Group } & \multicolumn{6}{|c|}{ Peak (eV) } & \multirow[t]{2}{*}{ FWHM } \\
\hline & $\mathrm{TiO}_{2}$ & $(\mathrm{OH})^{\prime} \mathrm{s}, \mathrm{C}-\mathrm{O}$ & $\mathrm{TiOH}, \mathrm{C}=\mathrm{O}$ & $\mathrm{O}^{2-}$ & $\mathrm{PO}_{4}, \mathrm{CO}_{3}, \mathrm{OH}$ & $\mathrm{H}_{2} \mathrm{O}$ & \\
\hline 1 & 530.36 & 532.13 & 534.09 & & & & 2.10 \\
\hline 2 & 530.49 & 531.94 & 533.26 & & & & 1.90 \\
\hline 3 & 530.00 & 531.15 & 532.75 & & & & 2.00 \\
\hline 4 & & & & 529.50 & 531.60 & 533.00 & $4.40 / 2.60 / 4.40$ \\
\hline 5 & 530.17 & 531.47 & 532.54 & & & & 1.60 \\
\hline
\end{tabular}

Table 4. Binding energy and FWHM of Ti $2 p 1 / 2$ components, as determined after curve fitting of the XPS high resolution spectra (see text for details).

\begin{tabular}{ccccc}
\hline \multirow{2}{*}{ Group } & \multicolumn{3}{c}{ Peak (eV) } & FWHM \\
\cline { 2 - 4 } & $\mathbf{T i O}_{2}$ & $\mathbf{T i}_{2} \mathbf{O}_{3}+\mathbf{T i O}$ & Ti metal & \\
\hline 1 & 464.50 & 462.50 & 460.50 & 2.20 \\
2 & 464.74 & 463.08 & 461.65 & 2.61 \\
3 & 464.45 & 462.63 & 460.81 & 2.10 \\
5 & 464.57 & 462.94 & 461.48 & 2.00 \\
\hline
\end{tabular}

the present study, the surface elements at the dental implants mainly consisted of $\mathrm{Ti}, \mathrm{O}$ and $\mathrm{C}$. The spectra of all groups were dominated by $\mathrm{Ti}$ and $\mathrm{O}$ due to the naturally formed $\mathrm{TiO}_{2}$ layer. Concentrations of oxygen, carbon and titanium on the surface of the implant groups showed differences that can be attributed to the different processes they are subjected during the fabrication process. The presence of silicon found on the surface of group 4 implants is mainly due to the contamination coming from manufacturing processes, surface treatment and sterilization ${ }^{25}$.

A thin layer of titanium oxide was observed in all implant groups, except group 4. The reason for this absence was the fact that the XPS technique is very sensitive to the most superficial region of a material, and the implants from group 4 had a HA layer completely covering the titanium, thick enough to avoid the underneath substrate to be detected by XPS. There is evidence that various properties of titanium oxide in fact lead to different biological responses at several levels, including biomolecular interactions, cellular behavior, tissue response and biomechanical stability ${ }^{6}$. This thin oxide film, naturally formed on a titanium substrate, is presumably responsible for the excellent biocompatibility of titanium implants due to a low level of electronic conductivity ${ }^{26}$, a high corrosion resistance and a thermodynamically stable state at physiological $\mathrm{pH}$ values ${ }^{27}$. The differences in the percentage content between the implants analyzed here were considered to be related to the different methods of surface modification performed by each manufacturer. The speed and pressure of the instrumentation applied in the surface modifications, surface temperature exposure to air, lubricants and coolants used, all together influence the nature of the implant surface ${ }^{28}$. The titanium spontaneously forms a passivating oxide layer at ambient
Table 5. Binding energy $\left(E_{\mathrm{p}}\right)$ and FWHM of Ti 2p3/2, as determined after curve fitting of the XPS high resolution spectra (see text for details).

\begin{tabular}{ccccc}
\hline \multirow{2}{*}{ Group } & \multicolumn{3}{c}{ Peak (eV) } & \multirow{2}{*}{ FWHM } \\
\cline { 2 - 4 } & $\mathbf{T i O}_{2}$ & $\mathbf{T i}_{2} \mathbf{O}_{\mathbf{3}}+\mathbf{T i O}$ & $\mathbf{T i ~ m e t a l}$ & \\
\hline 1 & 458.48 & 456.10 & 453.80 & 2.20 \\
2 & 458.83 & 455.85 & 450.00 & 2.61 \\
3 & 458.60 & 456.35 & 454.05 & 2.10 \\
5 & 458.70 & 456.70 & 454.26 & 2.00 \\
\hline
\end{tabular}

temperatures when exposed to air or water ${ }^{23}$. The XPS high-resolution spectra are dominated by a doublet peak at $\sim 459$ and $\sim 464 \mathrm{eV}$, which can be assigned to $\mathrm{TiO}_{2}$ (Ti 2p3/2 and Ti 2p1/2, respectively). A difference of 5.8 to $6.0 \mathrm{eV}$ in binding energies between the $\mathrm{Ti} 2 \mathrm{p} 3 / 2$ and $\mathrm{Ti} 2 \mathrm{p} 1 / 2$ peaks of the doublet further corroborated the presence of $\mathrm{TiO}_{2}$ on all the surfaces ${ }^{29}$. The XPS measurements indicate that the titanium implants from the group 4 coated by the HA-blasting process are completely covered by HA, because no Ti peaks are observed in the XPS spectra.

Minor contributions are frequently detected. These spectral features may be fitted (by peak deconvolution) to other oxidation states such as $\mathrm{TiO}, \mathrm{Ti}_{2} \mathrm{O}_{3}$, Ti hydroxide, $\mathrm{Ti}$ nitride, or $\mathrm{Ti}$ carbide ${ }^{6}$. In addition to $\mathrm{TiO}_{2}, \mathrm{Ti}_{2} \mathrm{O}_{3}$ and $\mathrm{TiO}$ were also detected. The relative intensities of these components are shown in Table 6. Hydrated water (Ti-OH) and hydroxides $(\mathrm{OH})$ were obtained by deconvolution of Ti 2 p and $\mathrm{O} 1 \mathrm{~s}$. Olefjord and Hansson ${ }^{22}$ demonstrated that the outer oxide layers of Brånemark and IMZ implants were $\mathrm{TiO}_{2}$, using an ESCA instrument, and this was confirmed by the study of Sawase et al. ${ }^{23}$. These layers were considered to be formed during production and handling of implant products $^{23}$. At Ti $2 \mathrm{p}$, the peaks approximately corresponded to the binding energy of $\mathrm{TiO}_{2}$. There were, however, minute differences of less than $0.5 \mathrm{eV}$ between detected peaks and binding energy of $\mathrm{TiO}_{2}$. Contamination by some carbonic complexes adhering to the implant surface might cause the minute charge shifts due to their insulating effects. The observed chemical shift between the oxide peak and the metal peak agrees well with the expected value for $\mathrm{TiO}_{2}{ }^{30}$.

The oxygen envelope for all surfaces usually had at least three components (sub-peaks). Sub-peaks at $530 \mathrm{eV}$ were identified in groups $1,2,3$, and 5 . The presence of hydroxides is indicated by the shape of the $\mathrm{O}$ ls peak for 
Table 6. Relative peak areas of Ti 2p and O 1s components as determined by XPS analysis.

\begin{tabular}{|c|c|c|c|c|c|c|c|c|c|}
\hline \multirow[t]{3}{*}{ Group } & \multicolumn{9}{|c|}{ Relative peak area $(\%)$} \\
\hline & \multicolumn{3}{|c|}{ Ti $2 p$} & \multicolumn{6}{|c|}{ O 1s } \\
\hline & $\mathrm{TiO}_{2}$ & $\mathrm{Ti}_{2} \mathrm{O}_{3}+\mathrm{TiO}$ & Ti metal & $\mathrm{TiO}_{2}$ & $(\mathrm{OH}), \mathrm{C}-\mathrm{O}$ & Ti-OH, C $=\mathbf{O}$ & $\mathbf{O}^{2-}$ & $\mathrm{PO}_{4}, \mathrm{OH}$ & $\mathrm{H}_{2} \mathrm{O}$ \\
\hline 1 & 62.1 & 13.6 & 24.2 & 61.8 & 33.9 & 4.3 & - & - & - \\
\hline 2 & 64.9 & 24.6 & 10.5 & 60.8 & 30.4 & 8.8 & - & - & - \\
\hline 3 & 63.7 & 15.3 & 20.9 & 77.0 & 17.5 & 5.4 & - & - & - \\
\hline 4 & - & - & - & - & - & - & 42.3 & 36.5 & 21.2 \\
\hline 5 & 84.0 & 10.2 & 5.9 & 56.1 & 28.8 & 15.1 & - & - & - \\
\hline
\end{tabular}

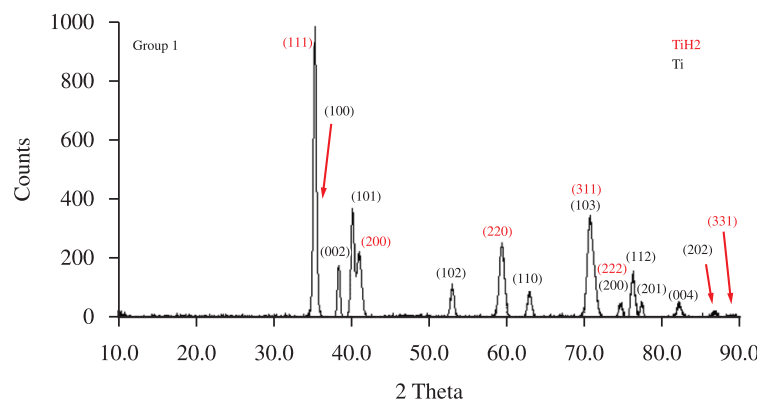

(a)

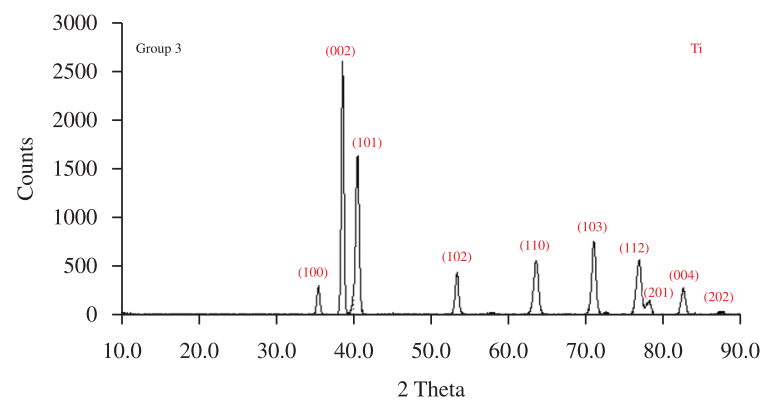

(c)

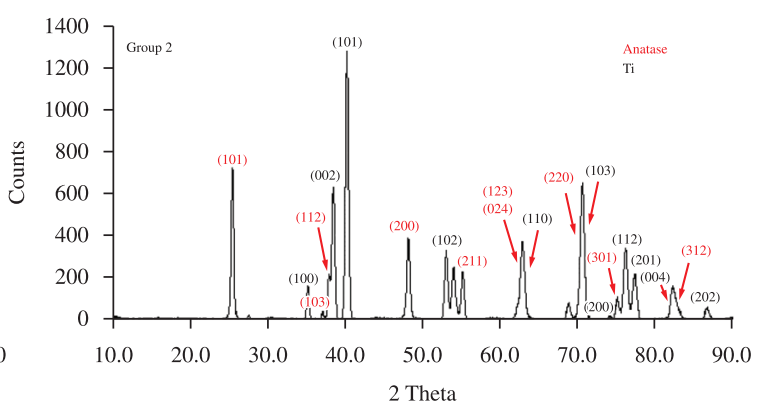

(b)

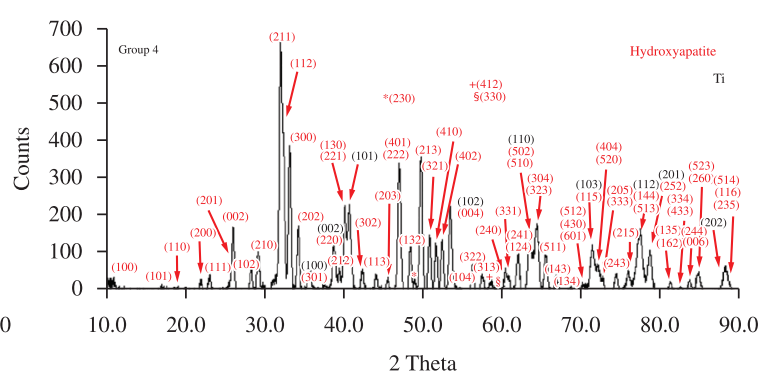

(d)

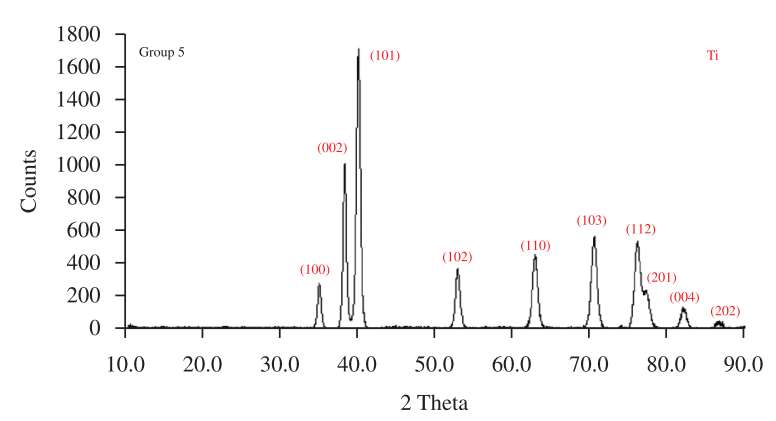

(e)

Figure 3. Typical XRD pattern for samples from group 1 to 5 , a) to e) respectively.

these surfaces, which frequently shows spectral components between 531 and $533 \mathrm{eV}$, assigned to $\mathrm{OH}$ and $\mathrm{H}_{2} 0$, respectively ${ }^{31}$. These results thus show that surface oxides on titanium implants should not generally be expected to have a pure $\mathrm{TiO}_{2}$ stoichiometry. The $\mathrm{O} 1 \mathrm{~s}$ spectrum of group 4 was deconvoluted to $\mathrm{O}^{2-},\left(\mathrm{PO}_{4}, \mathrm{CO}_{3}\right.$ and $\left.\mathrm{OH}\right)$, and $\mathrm{H}_{2} \mathrm{O}$, ${ }^{9}$ and showed no $\mathrm{TiO}_{2}$ sub-peak. This unique deconvolution present only in this group is probably due to HA-blasting method performed by the manufacturer; the surface was completely covered by HA.

Some authors have used the difference between the binding energy $(\triangle \mathrm{BE})$ of an $\mathrm{O}$ 1s sub-peak and the corresponding Ti 2 p 3/2 peak to identify chemical states. $\mathrm{TiO}_{2}$ has been referenced with a value of $71.5 \mathrm{eV}^{29}$. The 
present results from the samples of all groups corresponded to this value.

Deconvolution of high resolution spectra of the carbon 1s peaks revealed three components for each surface: $\mathrm{C}=\mathrm{O}$, $\mathrm{C}-\mathrm{O}$ or $\mathrm{C}-\mathrm{OH}$, and $\mathrm{C}-\mathrm{C}$ (graphite) or $\mathrm{CH}$ (hydrocarbon) ${ }^{6,29}$. The binding energies for these three components in the present study were $\sim 288.53, \sim 286.80$, and $\sim 285.00 \mathrm{eV}$, respectively. The concentration of the hydrocarbon layer was abruptly decreased after Ar sputtering, which indicates that its source probably was due to adsorption of carbon compounds from the ambient air, and was mainly located on the oxide surface. This degree of contamination is conformal to the percentages found after a common process of surface cleaning ${ }^{32}$.

\subsection{XRD analysis}

The absence of peaks of $\mathrm{Ca}$ and $\mathrm{P}$ phases in the X-ray diffractograms of the implants in groups 2 to 5 , was observed, while the XPS analysis showed the presence of these elements. This happened because the layer of $\mathrm{Ca}$ and $\mathrm{P}$ implants formed in groups 2,3 , and 5 is very thin as to not be detected by XRD technique. In the case of a very thin layer on the surface, the XRD would show only the signal of the substrate while the XPS would be very sensitive to the surface chemical composition (few nanometers deep). In the case of group 4, $\mathrm{Ca}$ and $\mathrm{P}$ were present in the hydroxyapatite. The results of XRD and XPS suggest that the coating layer in implants from group 4 is thicker than the other groups.

A coating process was developed in which HA was blasted at a surface using standard sand blasting equipment, and this was found to produce a HA coating which showed promising results in vivo ${ }^{33}$. This was the method used (announced) by the implant manufacturer of the group 4 to incorporate HA on titanium surface. The fact that the bioactive agent can be deposited unaltered suggests that the technique could be used to deposit active therapeutic and biologic agents ${ }^{33}$. The method used by the manufacturer of group 4 implants (HA-blasting) was efficient for this purpose.

It has been reported that the etching process modifies the Ti surface composition of SLA-treated implants, and $\mathrm{X}$-ray diffraction (XRD) and metallographic microscopy analysis indicated the presence of 20 to $40 \%$ of titanium hydride $\left(\mathrm{TiH}_{\mathrm{x}}, \mathrm{x} \leq 2\right)$ in addition to $\mathrm{Ti}^{34}$ As the surface of the implants in group 1 were also modified by double acid etching as the SLA-treated implants, it is not surprising to find titanium hydride in the implants from this group.

In one study ${ }^{35}, \mathrm{TiO}_{2}$ layers were treated by annealing for 2 hours in air at 600 and $1000{ }^{\circ} \mathrm{C}$, which produce the anatase and rutile phases, respectively. The quasi-amorphous oxides can be crystallized by heating, which explains why anatase was found in the group 2 of implants, since it was subjected to an anodizing process. The manufacturer of this group has not disclosed, but an annealing is done after anodizing in order to obtain the anatase phase, because it has some biological advantages: the anatase phase of titania film enhances osteoblast adhesion, proliferation and differentiation by affecting surface contact angles and/or wettability ${ }^{36}$.
According to recent review made by Junker et al. ${ }^{37}$, there is sufficient proof that surface roughening induces a safe and predictable implant-to-bone response, but it is not clear whether this effect is due to the surface roughness or to the related change in the surface composition. The review of the experimental surface alterations revealed that thin $\mathrm{CaP}$ coating technology can solve the problems associated with thick $\mathrm{CaP}$ coatings, while they still improve implant bone integration compared with non-coated titanium implants. Moreover, it has been documented that HA-coated implants have higher osseoconductive properties when compared with uncoated implants ${ }^{38,39}$, and even when compared with CaP-coated implants ${ }^{39}$. In one study ${ }^{38}$, primary human osteoblast-like cells incubated on the HA-coated titanium appeared to exhibit the highest number of cell process attaching to the surface in comparison with three other different titanium surfaces (as-machined, $\mathrm{Al}_{2} \mathrm{O}_{3}$-blasted, and plasma-sprayed with titanium particles), which was indicative of optimal cell attachment on HA. Considering this set of information, the results presented here suggest the group 4 of implants (HA-coated dental implants) may have the more suitable characteristics for faster osseointegration.

\section{Conclusions}

It was confirmed considering the experimental results present here, that the titanium with different coatings show a wide range of chemical, physical properties, and surface topographies or morphologies, depending on how they are prepared and handled. Furthermore, by using different surface preparation methods it is possible to control and vary specific surface properties of titanium over a relatively wide range. Different chemical properties of protective layer of titanium-based implants analyzed in this study show different behavior of deposited layer. The XPS analysis showed that the surface of the implants studied were mainly composed of a layer of $\mathrm{TiO}_{2}$, but there are other oxides associated with a lesser amount as $\mathrm{TiO}$ and $\mathrm{Ti}_{2} \mathrm{O}_{3}$. Organic contamination was observed on all surfaces which is not surprising as every titanium (oxide) surface exposed to air will adsorb hydrocarbons or carbon-oxygen containing species from air. Different concentrations of calcium and phosphor were measured on the surface of some samples, because this kind of characterization is used by each manufacturer in order to produce a bone conductor substrate. From XRD results in the present study, the HA-blasting method used (announced) by the implant manufacturer of the group 4 to incorporate HA on titanium surface seems to be an efficient method for this purpose.

According to the manufacturers, the addition of $\mathrm{Ca}$ and $\mathrm{P}$ at the implant surface is a main feature of these implants (groups 2 to 5). However, the results showed a great discrepancy on the final amount of these elements on the implant surface, which suggests a different effectiveness of the employed surface finishing methods to fix these elements on the implant surface tested here. All manufacturers of this study that tried to incorporate $\mathrm{Ca}$ and $\mathrm{P}$ on the titanium implant surface (groups 2, 3, 4 and 5) succeeded, according to the results presented by the EDS. 
But only the manufacturer of the group 4 implants could effectively incorporate HA on titanium. The other groups (2, anodization and incorporation of $\mathrm{Ca} / \mathrm{P} ; 3$, acid etching and deposition of $\mathrm{Ca} / \mathrm{P}$; and $5, \mathrm{Ca} / \mathrm{P}$-blasting and acid etching) yielded only the formation of superficial amorphous $\mathrm{Ca} / \mathrm{P}$ complex. The implants from group 4 also showed the highest roughness parameters.

\section{References}

1. Orsini G, Piattelli M, Scarano A, Petrone G, Kenealy J, Piattelli A et al. Randomized, controlled histologic and histomorphometric evaluation of implants with nanometer-scale calcium phosphate added to the dual acid-etched surface in the human posterior maxilla. Journal of Periodontology. 2007; 78(2):209-218. PMid:17274708. http://dx.doi.org/10.1902/jop.2007.060297

2. Albrektsson $\mathrm{T}$ and Johansson C. Osteoinduction, osteoconduction and osseointegration. European Spine Journal. 2001; 10(Suppl 2):S96-S101. PMid:11716023. http:// dx.doi.org/10.1007/s005860100282

3. Stanford CM. Surface modification of biomedical and dental implants and the processes of inflammation, wound healing and bone formation. International Journal of Molecular Sciences. 2010; 11(1):354-369. PMid:20162020. PMCid:2821008. http://dx.doi.org/10.3390/ijms11010354

4. Wennerberg A and Albrektsson T. Effects of titanium surface topography on bone integration: a systematic review. Clinical Oral Implants Research. 2009; 20(Suppl 4):172-184. PMid:19663964. http://dx.doi.org/10.1111/j.16000501.2009.01775.x

5. Albrektsson T, Brånemark PI, Hansson HÁ and Lindstöm J. Osseointegrated titanium implants. Requirements for ensuring a long-lasting, direct bone-to-implant anchorage in man. Acta Orthopaedica Scandinavica. 1981; 52(2):155-170. http:// dx.doi.org/10.3109/17453678108991776

6. Lausmaa J. Surface spectroscopic characterization of titanium implant materials. Journal of Electron Spectroscopy and Related Phenomena. 1996; 81(3):343-361. http://dx.doi. org/10.1016/0368-2048(95)02530-8

7. Moulder JF, Stickle WF, Sobol PE and Bomben KD. Handbook of X-ray Photoelectron Spectroscopy. Minnesota: Perkin-Elmer Corporation, Physical Electronics Division; 1992.

8. Cullity BD and Stock SR. Chapter 10: The Determination of Crystal Structure. In: Cullity BD, Stock SR. Elements of X-Ray Diffraction. 3th ed. Reading: Addison-Wesley Publishing; 1956. p. 297-323.

9. Ka iulis S, Mattogno G, Pandolfi L, Cavalli, M, Gnappi $\mathrm{G}$ and Montenero A. XPS study of apatite-based coatings prepared by sol-gel technique. Applied Surface Science. 1999; 151(5):1-5.

10. Castilho GAA, Martins MD and Macedo WAA. Surface characterization of titanium based dental implants. Brazilian Journal of Physics. 2006; 36(3b):1004-1008. http://dx.doi. org/10.1590/S0103-97332006000600055

11. Massaro C, Rotolo P, De Riccardis F, Milell E, Napoli A, Wieland $\mathrm{M}$ et al. Comparative investigation of the surface properties of commercial titanium dental implants. Part I: chemical composition. Journal of Materials Science: Materials in Medicine. 2002; 13(6):535-548. PMid:15348583. http:// dx.doi.org/10.1023/A:1015170625506

\section{Acknowledgements}

This work was supported by the Brazilian agencies CNPq and FAPEMIG. The authors would like to thank Sai Sunil Kumar, Renato de Mendonça, Éden Cristiano Costa, Mário da Silva Araújo Filho, and Antônio Luis Neto Custódio.

12. Peters M, Hemptenmacher J, Kumpfert J and Leyens C. Chapter 1. Structure and Properties of Titanium and Titanium Alloys. In: Leyens C, Peters M, editors. Titanium and Titanium Alloys: Fundamentals and Applications. Weinheim: Wiley-VCH; 2003. p. 1-36.

13. Li DH, Lin J, Lin DY and Wang XX. Synthesized silicon-substituted hydroxyapatite coating on titanium substrate by electrochemical deposition. Journal of Materials Science: Materials in Medicine. 2011; 22(5):1205-1211. PMid:21465241. http://dx.doi.org/10.1007/s 10856-0114310-y

14. Kim KJ and Park YR. Structural and optical properties of rutile and anatase $\mathrm{TiO}_{2}$ thin films: effects of Co doping. Thin Solid Films. 2005; 484(1-2):34-38. http://dx.doi.org/10.1016/j. tsf.2005.01.039

15. Kovalev DY, Prokudina VK, Ratnikov VI and Ponomarev VI. Thermal Decomposition of $\mathrm{TiH}_{2}$ : A TRXRD Study. International Journal of Self-Propagating High-Temperature Synthesis. 2010; 19(4):253-257. http://dx.doi.org/10.3103/ S1061386210040047

16. Aparicio C, Padrós A and Gil FJ. In vivo evaluation of micro-rough and bioactive titanium dental implants using histometry and pull-out tests. Journal of Mechanical Behaviour of Biomedical Materials. 2011;4(8):1672-1682. PMid:22098868. http://dx.doi.org/10.1016/j.jmbbm.2011.05.005

17. Wennerberg A. On roughness and implant incorporation. [Tese]. Göteborg: Göteborg University; 1996.

18. Wennerberg A, Albrektsson T and Lausmaa J. Torque and histomorphometric evaluation of c.p. titanium screws blasted with 25- and 75- $\mu \mathrm{m}$-sized particles of $\mathrm{Al}_{2} \mathrm{O}_{3}$. Journal of Biomedical Materials Research. 1996; 30(2):251-260. http://dx.doi. org/10.1002/(SICI)1097-4636(199602)30:2\%3C251::AIDJBM16\%3E3.0.CO;2-P

19. Wennerberg A, Hallgren C, Johansson C and Danelli S. A histomorphometric evaluation of screw shaped implants each prepared with two surface roughness. Clinical Oral Implants Research. 1998; 9(1):11-19. PMid:9590940. http://dx.doi. org/10.1034/j.1600-0501.1998.090102.x

20. Gotfredsen K, Berglundh T and Lindhe J. Anchorage of titanium implants with different surface characteristics: an experimental study in rabbits. Clinical Implant Dentistry and Related Research. 2000; 2(3):120-128. PMid:11359256. http:// dx.doi.org/10.1111/j.1708-8208.2000.tb00002.x

21. Wróbel E, Witkowska-Zimny M and Przybylski J. Biological mechanisms of implant osseointegration. Ortopedia Traumatologia Rehabilitacja. 2010; 12(5):401-409. PMid:21057147.

22. Olefjord I and Hansson S. Surface analysis of four dental implant systems. The International Journal of Oral and Maxillofacial Implants. 1993; 8(1):32-40. PMid:8468084.

23. Sawase T, Hai K, Yoshida K, Baba K, Hatada R and Atsuta M. Spectroscopic studies of three osseointegrated implants. 
Journal of Dentistry. 1998; 26(2):119-124. http://dx.doi. org/10.1016/S0300-5712(96)00080-2

24. Sul YT, Johansson C, Chang BS, Byon ES and Jeong Y. Bone tissue responses to $\mathrm{Mg}$-incorporated oxidized implants and machine-turned implants in the rabbit femur. Journal of Applied Biomaterials and Biomechanics. 2005; 3(1):18-28. PMid:20799236.

25. Keller JC, Draughn RA, Wightman JP, Dougherty WJ and Meletiou SD. Characterization of sterilized CP titanium implant surfaces. The International Journal of Oral Maxillofacial Implants. 1990; 5(4):360-367. PMid:2094654.

26. Zitter $\mathrm{H}$ and Plenk HJ. The electrochemical behaviour of metallic implant materials as indicator of their biocompatibility. Journal of Biomedical Materials Research. 1987; 21(7):881-896. PMid:3611146. http://dx.doi.org/10.1002/jbm.820210705

27. Solar RJ, Pollack SR and Korostoff E. In vitro corrosion testing of titanium surgical implant alloys: an approach to understanding titanium release from implants. Journal of Biomedical Materials Research. 1979; 13(2):217-250. PMid:429392. http://dx.doi.org/10.1002/jbm.820130206

28. Kasemo B and Lausmaa J. Biomaterial and implant surfaces: on the role of cleanliness, contamination, and preparation procedures. Journal of Biomedical Materials Research. 1988; 22(A2 Suppl):145-158.

29. Ong JL, Lucas LC, Raikar GN and Gregory JC. Electrochemical corrosion analyses and characterization of surface modified titanium. Applied Surface Science. 1993; 72(1):7-13. http:// dx.doi.org/10.1016/0169-4332(93)90036-B

30. Carley AF, Chalker PR, Riviere JC and Roberts MW. The identification and characterization of mixed oxidation states at oxidised titanium surfaces. Journal of Chemical Society, Faraday Transactions 1: Physical Chemistry in Condensed Phases. 1987; 83(2):351-370.

31. Sham TK and Lazarus MS. X-ray photoelectron spectroscopy (XPS) studies of clean and hydrated $\mathrm{TiO}_{2}$ (rutile) surfaces. Chemical Physics Letters. 1979; 68(2-3):426-432. http://dx.doi. org/10.1016/0009-2614(79)87231-0

32. Cacciafesta P, Hallam KR, Oyedepo CA, Humphris ADL, Mervyn JM and Jandt KD. Characterization of ultraflat titanium oxide surfaces. Chemistry of Materials. 2002; 14(2):777-789.
33. O'Hare P, Meenan BJ, Burke GA, Byrne G, Dowling D and Hunt JA. Biological responses to hydroxyapatite surfaces deposited via a co-incident microblasting technique. Biomaterials. 2010; 31(3):515-522. PMid:19864018. http:// dx.doi.org/10.1016/j.biomaterials.2009.09.067

34. Perrin D, Szmukler-Moncler S, Echikou C, Pointaire P and Bernard JP. Bone response to alteration of surface topography and surface composition of sandblasted and acid etched (SLA) implants. Clinical Oral Implants Research. 2002; 13(5):465-469. PMid:12453122. http://dx.doi. org/10.1034/j.1600-0501.2002.130504.x

35. Nam SH, Choi JW, Cho SJ, Kimt KS and Boo JH. Growth of $\mathrm{TiO}_{2}$ anti-reflection layer on textured $\mathrm{Si}(100)$ wafer substrate by metal-organic chemical vapor deposition method. Journal of Nanoscience and Nanotechnology. 2011;11(8):73157318. PMid:22103185. http://dx.doi.org/10.1166/ jnn.2011.4813

36. He J, Zhou W, Zhou X, Zhong X, Zhang X, Wan P et al. The anatase phase of nanotopography titania plays an important role on osteoblast cell morphology and proliferation. Journal of Materials Science: Materials in Medicine. 2008; 19(11):3465-3472. PMid:18592349. http:// dx.doi.org/10.1007/s10856-008-3505-3

37. Junker R, Dimakis A, Thoneick M and Jansen JA. Effects of implant surface coatings and composition on bone integration: a systematic review. Clinical Oral Implants Research. 2009; 20(Suppl 4):185-206. PMid:19663965. http:// dx.doi.org/10.1111/j.1600-0501.2009.01777.x

38. Prado Da Silva MH, Soares GD, Elias CN, Best SM, Gibson IR, DiSilvio L et al. In vitro cellular response to titanium electrochemically coated with hydroxyapatite compared to titanium with three different levels of surface roughness. Journal of Materials Science: Materials in Medicine. 2003;14(6):511-519. http://dx.doi. org/10.1023/A:1023455913567

39. Yang GL, He FM, Hu JA, Wang XX and Zhao SF. Biomechanical comparison of biomimetically and electrochemically deposited hydroxyapatite-coated porous titanium implants. Journal of Oral and Maxillofacial Surgery. 2010; 68(2):420-427. PMid:20116717. http://dx.doi. org/10.1016/j.joms.2009.09.014 